\title{
Educação para a geoconservação: reflexões da experiếncia no Parque Estadual da Serra do Mar (SP)
}

\author{
Eliana Mazzucato ${ }^{1}$, Denise de La Corte Baccl², Vânia Maria Nunes dos Santos ${ }^{3}$ \\ 1 - Mestre em Geociências, Instituto de Geociências, Universidade de São Paulo, 05508-080, São Paulo, SP, Brasil. \\ 2 - Depto. Geologia Sedimentar e Ambiental, Universidade de São Paulo, 05508-080, São Paulo, SP, Brasil. \\ 3 - Doutora em Ciências e Professora Permanente do Programa de Pós Graduação em Ensino e História de Ciências da Terra, Instituto de Geociências, Universidade \\ Estadual de Campinas, 13083-855, Campinas, SP, Brasil. \\ E-MAILS: ELIANA.MAZZUCATO@GMAll.com, BACCI@USP.BR, vania.mNSANTOS@Gmall.com
}

Abstract: This article aims to report and analyze the experience of elaboration, planning and application of the course "Geoconservation strategies in Serra do Mar State Park", which was carried out among 2016 and 2017 in Picinguaba and Caraguatatuba Center and in a public elementary school at Ubatuba. This course has consisted of the valorization and dissemination of geological heritage and the local geodiversity based on the inventories already developed in the study area. The approach was based on principles of the Social Learning for encouraging the Geoconservation in this area. The development of the course was based on geoscientific education; interpretation and dissemination of the geodiversity; knowledge and experiences valorization of locals actors; and in the participation these actors in educative proposals for the conservation.

\begin{abstract}
Manuscript:
Received: VIII Simpósio Nacional de Ensino e História de Ciências da Terra / EnsinoGE0-2018. Geociências para Todos Accepted: 14/01/2018

Citation: Mazzucato E., Bacci D.C. , Santos V.M.N. 2018. Educação para a geoconservação: reflexões da experiência no Parque Estadual da Serra do Mar (SP).Terræ Didatica, 14(4):417-426. URL: http:// www.ige.unicamp.br/terraedidatica/.
\end{abstract}

Keywords: Geoconservation, Serra do Mar State Park, Participation, Propagation courses.

Thematic line: Geoconservation, Geotourism and Geopatrimony.

\section{Introdução}

As estratégias de Geoconservação consistem em etapas voltadas para a conservação dos aspectos abióticos da natureza. De acordo com Brilha (2005), sua consolidação requer metodologia sistemática, que fundamente os elementos prioritários para a Geoconservação, seja por motivos científicos, educativos ou turísticos. As etapas iniciais consistem, portanto, no inventário e na quantificação do patrimônio geológico. Essa identificação celebra-se nas etapas de conservação, tendo em vista os aspectos legais de proteção e conservação, bem como de valorização e divulgação, que consistem em estratégias direcionadas ao público em geral. No entanto, destaca-se também a relevância do monitoramento da implementação dessas etapas e de sua efetividade.

O esforço proveniente da comunidade acadêmica para implantar essas estratégias no Brasil tem apresentado amplos avanços, repercutindo no âmbito institucional. Destacam-se as ações pioneiras de levantamento da geodiversidade nacional fomentadas pela Companhia de Pesquisas de Recursos Minerais (CPRM) e pela Comissão Brasileira de Sítios Geológicos e Paleontológicos (SIGEP) em conjunto com a comunidade geocientífica (Shobbenhaus et al. 2002, Winge et al. 2009, Winge et al. 2013).

Neste trabalho, será dado destaque às ações de valorização e divulgação do patrimônio geológico e da geodiversidade. Segundo Brilha (2005), na valorização promove-se a interpretação do patrimônio geológico observado, utilizando-se de painéis interpretativos, percursos temáticos, folhetos e informações digitais. De acordo com o mesmo autor, na divulgação, procuram-se meios de comunicar e informar o público.

Mansur et al. (2013) destacam algumas iniciativas brasileiras de desenvolvimento destas etapas, como por exemplo, os levantamentos da SIGEP que disponibilizaram as informações na internet e em livros impressos, atingindo muitas vezes o setor público e privado. O Projeto Geoparques (Schobbenhaus e Silva 2012), pois além de promover a identificação dos geossítios, os possíveis locais recebem ações de valorização e divulgação. 
O Projeto Caminhos Geológicos no Rio de Janeiro, que promoveu a instalação de painéis interpretativos e contou com ações de ensino e popularização científica junto à comunidade escolar, à sociedade civil e à governança local. O Projeto Sítios Geológicos e Paleontológicos do Paraná, com produção de folhetos, painéis e roteiros geoturísticos.

Nesse percurso, observa-se que a valorização e divulgação possui maior efetividade quando há um conhecimento preliminar na área de Geociências por parte do público alvo, por mais que essas ações se utilizem ou desenvolvam materiais didáticos com uma linguagem acessível. Nesse sentido, exemplificam-se as investigações de Santos (2006, 2011) e Soares (2016), que se propuseram a desenvolver curso de formação continuada de professores em exercício na área de Geociências, tendo como locus a proposta do Geoparque Ciclo do Ouro em Guarulhos (Aguilar et al. 2012). O curso constituiu-se em estratégia de longo prazo, consolidando saberes em conjunto com os professores da rede pública de ensino e preparando-os para interpretar a geodiversidade próxima da escola, promovendo a Geoconservação.

Nota-se também as contribuições de Avelar et al. (2016) que coletaram dados junto às comunidades do entorno da área proposta a Geoparque "Costões e Lagunas do Estado do Rio de Janeiro" (Mansur et al. 2012). Na abordagem, os autores valorizam o conhecimento local a respeito das características ambientais, econômicas e culturais da área, e as atividades humanas que afetam esse ambiente, contribuindo com o desenvolvimento de ações específicas de Geoconservação na área.

Tais experiências demonstram um compromisso com a perspectiva socioambiental da conservação da natureza, pois propõem um maior diálogo com as populações que serão envolvidas nas estratégias de Geoconservação. Valorizam diagnósticos locais e participativos, levantando os conflitos locais que desencadeiam os impactos e as ameaças à natureza, bem como reconhecem a relação de pertencimento e a valorização cultural para com a geodiversidade.

Alinhado a estes pensamentos, esta pesquisa teve o objetivo de consolidar uma estratégia de Geoconservação baseada no diálogo e na participação das pessoas no sentido de ampliar o reconhecimento da geodiversidade, pautados nas relações socioculturais estabelecidas com os elementos locais da geodiversidade.

Essa proposta é consoante aos princípios socio- ambientais da conservação da natureza (Carvalho 2008) por agregar ao fator ambiental as relações estabelecidas e o sentimento de pertencimento que contribuem para a valorização do lugar.

A experiência relatada neste trabalho é parte dos resultados da dissertação de Mestrado intitulada "Estratégias de Geoconservação no Parque Estadual da Serra do Mar" de Mazzucato (2017), no Instituto de Geociências da USP.

O curso foi desenvolvido na área do PESM, nos núcleos Picinguaba e Caraguatatuba (Fig. 1), que abrangem respectivamente $80 \%$ da área de Ubatuba e 78,29\% de Caraguatatuba. O núcleo Caraguatatuba também se insere em trechos dos municípios de Paraibuna e Natividade da Serra, no Estado de São Paulo.

Essa área contém extensivos trabalhos de inventário e quantificação, no âmbito do inventário do patrimônio geológico do Estado de São Paulo (Garcia et al. 2017), e em pesquisas de mestrado e doutorado que realizaram inventários dos municípios ao qual esses núcleos estão inseridos em sua maior parcela (Santos 2014, Arruda 2017). Além disso, conta com ações de valorização e divulgação como a instalação de painéis de interpretação geológica. Ambas as ações têm como referência o Núcleo de Apoio à Pesquisa em Patrimônio Geológico e Geoturismo (NAP GeoHereditas) que se localiza no Instituto de Geociências da Universidade de São Paulo (IGc-USP).

Portanto, nosso questionamento partiu principalmente de como esses inventários poderiam orientar ações para contribuir com a conservação desses locais e, como os atores locais poderiam compreender a importância dessa conservação e inclusive participar dela.

A partir do diagnóstico socioambiental (Mazzucato 2017), percebeu-se a necessidade da realização de cursos para a divulgação de conhecimentos relacionados às Geociências e à Geoconservação para assim possibilitar o envolvimento desses atores locais nas estratégias de Geoconservação.

Com base nos dados obtidos na pesquisa de mestrado, este trabalho apresenta e discute o percurso de planejamento e desenvolvimento dos cursos realizados na área de estudo, bem como sua avaliação. Desse modo, buscou-se evidenciar como se deu sua construção, quais metodologias e estratégias de ensino foram adotadas, os fundamentos teóricos que os embasaram, considerando, assim, a importância de cursos voltados à formação dos atores locais para a Geoconservação. 


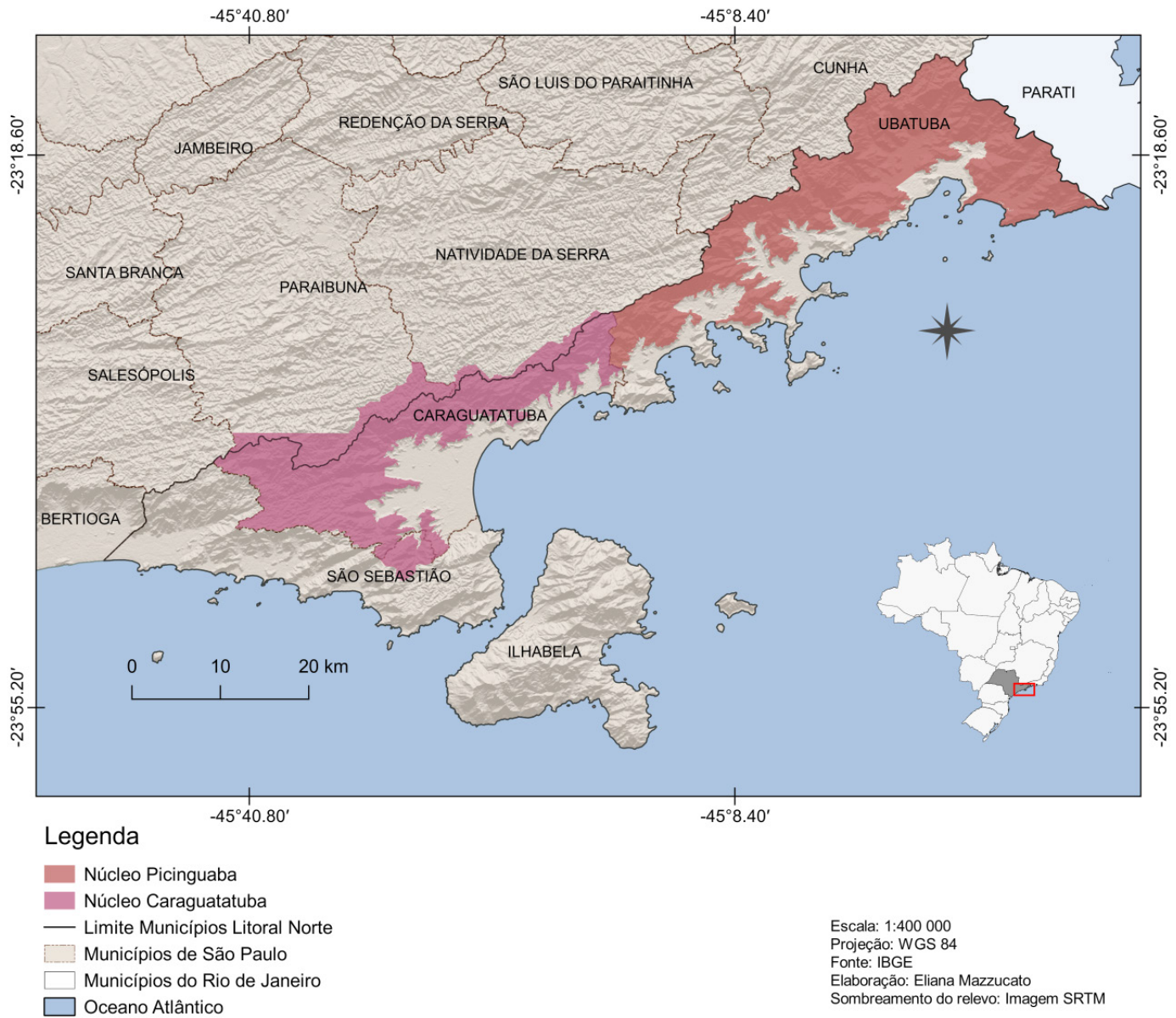

Figura 1. Mapa de localização da área de estudo. Fonte: Adaptado de Mazzucato (2017)

\section{Contexto e procedimentos adotados para a realização do Curso "Estratégias de Geoconservação no Parque Estadual da Serra do Mar"}

\subsection{Panorama da área de estudo}

O Parque Estadual da Serra do Mar (PESM) é uma Unidade de Conservação (UC) de Proteção Integral que foi criada em 1977 pelo Decreto Estadual $\mathrm{n}^{\circ}$ 10.251, inicialmente com cerca de 315 mil hectares. Em 2010, sua área foi ampliada para 332 mil hectares, incorporando áreas públicas, devolutas ou remanescentes de ações judiciais (São Paulo 2010).

O PESM é reconhecido como relevante reduto da Mata Atlântica, já dizimada em 93\% de seu total, corresponde assim à maior unidade de conservação desse bioma formando um corredor de preservação com 25 municípios, conectando florestas da Serra do Mar que vão desde o Paraná ao Rio de Janeiro. Essas áreas foram preservadas mesmo estando próximas às maiores metrópoles do País (São Paulo e Rio de Janeiro). Destaca-se a preservação do bioma e aspectos físicos de profunda relevância, como a preservação de mananciais, áreas de encosta suscetíveis à erosão e ambientes costeiros (São Paulo 2006).

Devido à sua abrangência territorial, o PESM foi compartimentado em núcleos com objetivo de facilitar a gestão diante de um território com características tão diversas. Atualmente o Parque conta com os seguintes núcleos: Caraguatatuba, Cunha, Curucutu, Itutinga-Pilóes, Picinguaba, Santa Virgínia, São Sebastião, Bertioga, Caminhos do Mar, Itariru e Padre Dória.

O núcleo Picinguaba possui uma área de 47.500 hectares, localiza-se no extremo norte do PESM. A região caracteriza-se por apresentar comunida- 
des tradicionais inseridas em seus limites, correspondendo a caiçaras e quilombolas além de áreas indígenas. Observa-se que nesse núcleo, a gestão da UC trata de forma peculiar a questão da presença de comunidades tradicionais, prevalecendo assim áreas em que esses grupos podem habitar e manter seus modos de vida respeitando especificações definidas no Zoneamento do Plano de Manejo do Parque (São Paulo 2006).

A área é referência na preservação dos remanescentes de Mata Atlântica do Estado de São Paulo associados às escarpas da Serra do Mar e, dos ecossistemas costeiros, restingas e manguezais. (São Paulo 2006)

O núcleo Caraguatatuba abrange uma área de 13.969,60 hectares, fazendo fronteira a norte com o núcleo Picinguaba e a sul, com o São Sebastião. Neste núcleo predominam áreas de morros e encostas da Serra do Mar, preservando matas de encosta, rios e cachoeiras, mananciais e sua paisagem como um todo. Neste núcleo não foram identificadas comunidades tradicionais de acordo com o Plano de Manejo, entretanto, observa-se áreas com residentes em situação temporária (São Paulo 2006).

Em termos geológicos, a área se insere na Faixa Ribeira, compreendendo a Província Mantiqueira (Almeida et al. 1977, Almeida et al. 1981) de idade neoproterozóica, destacando-se o Domínio Costeiro e as Coberturas Sedimentares Cenozóicas.

De acordo com Perrotta et al. (2005), pode-se observar que na área dos núcleos Caraguatatuba e Ubatuba afloram as unidades litoestratigráficas do Neoproterozoico, como Charnockito Ubatuba, Complexos Graníticos, Complexos Costeiros e Granitos. Além disso, observam-se unidades do Cenozoico, como depósitos aluvionares, coberturas detríticas e depósitos litorâneos.

\subsection{Etapas de planejamento do curso} foram:

As etapas que precederam a realização do curso

1. Análise da realidade socioambiental local;

2. Análise da geodiversidade e do patrimônio geológico local;

3. Estabelecimento de parcerias para viabilizar o curso;

4. Análise do perfil dos participantes;

5. Definição do referencial teórico e metodológico dos cursos;
6. Definição dos conteúdos, planos de aula e estratégias de ensino.

As duas primeiras etapas relacionam-se com o reconhecimento dos aspectos socioculturais e ambientais que compõem a realidade da área de estudo, que permitem uma abordagem mais direcionada.

Na primeira etapa, Mazzucato (2017) baseou-se na coleta de dados in loco e em dados de documentos oficiais. Os primeiros foram obtidos por meio de trabalhos de campo e entrevistas com moradores locais, refletindo sobre aspectos sociais, culturais e históricos, sobre a paisagem natural e suas transformações. Além disso, buscou-se a identificação dos atores locais envolvidos nos principais conflitos socioambientais. Os dados oficiais foram obtidos através de censos demográficos e levantamentos bibliográficos.

Durante a etapa 2, analisou-se os inventários elaborados por Santos (2014), Arruda (2017) e Garcia et al. (2017). Além disso, foram utilizadas outras referências bibliográficas de descrição geológica dessas localidades.

Nessa etapa também foram realizados trabalhos de campo para identificar e correlacionar as possíveis abordagens didáticas dos geossítios, e suas relações históricas e culturais com os moradores dos municípios.

Além disso, avaliaram-se as possibilidades para a realização dos cursos e do público alvo, considerando a necessidade de uma infraestrutura básica, como um local adequado, com sala de aula e/ou auditório. Outras necessidades eram fundamentais, como a forma de divulgação do curso, espaço adequado para realização de coffee break, proximidade com a área a ser analisada no trabalho de campo ou possibilidade de deslocamento.

Como o presente relato fez parte de uma pesquisa de mestrado que estava em andamento, observou-se um diálogo já iniciado entre os pesquisadores do NAP GeoHereditas e os gestores e outros funcionários do PESM. Desse modo, adotou-se uma postura de fortalecimento desse diálogo, o que culminou na estruturação de uma parceria com os núcleos Picinguaba e Caraguatatuba para a realização do curso.

Foi de interesse das UCs o oferecimento do curso para os monitores ambientais cadastrados no parque, sendo muitos deles prestadores de serviços e alguns funcionários da Fundação Florestal. Também foi acordado que o curso estaria aberto para outras pessoas que tivessem interesse pela temática, 
sendo atribuída às unidades a divulgação do curso. Configurou-se assim, uma oportunidade de desenvolvimento do ensino de Geociências e divulgação da geodiversidade e do patrimônio geológico em ambiente não escolar.

Com o objetivo de ampliar os atores locais envolvidos e de viabilizar uma experiência em ambiente escolar, optou-se por buscar escolas para o estabelecimento de parcerias e a realização do curso. A partir de diversas reuniões e tentativas, foi possível realizar o curso em uma escola de ensino fundamental localizada no município de Ubatuba que se mostrou interessada e ofereceu a infraestrutura básica para o seu desenvolvimento. Neste caso, o diálogo se deu diretamente com a diretoria da escola. O curso oferecido na escola municipal foi destinado aos seus professores e gestores, que atuam na Educação Infantil (EI) e Ensino Fundamental (EF), contemplando as diversas disciplinas do currículo.

Ambos os cursos foram cadastrados pelo Instituto de Geociências da USP como de difusão intitulado "Estratégias de Geoconservação no Parque Estadual da Serra do Mar", como ação do GeoHereditas.

A quarta etapa, de análise do perfil dos possíveis participantes no PESM revelou que o público alvo seria heterogêneo, no que diz respeito à idade, formação e tempo de experiência. Os monitores ambientais atuam principalmente no Uso Público do Parque, que se refere às atividades de ordenamento da visitação pública, como o ecoturismo, a educação ambiental, a prática de esportes de aventuras, programas de comunicação e divulgação, realização de eventos e desenvolvimento de pesquisas (São Paulo 2014). De acordo com São Paulo (2006, p. 201), o monitor ambiental é um "multiplicador de informações referentes à ecologia, questões sócio-ambientais e histórico-culturais do PESM e região". Por isso, esperava-se que esse público tivesse conhecimento específico da área de estudo, visto que possuem experiência em campo e que já orientam grupos com informações do parque e da natureza local.

Por norma, grande parte das trilhas dessas UCs requerem a contratação de um monitor, o que garante um percurso mais seguro, tanto para o ambiente, quanto para os visitantes. Além disso, durante o percurso, os monitores abordam questões sobre o parque, seu histórico, a importância da conservação, aspectos da fauna e flora local, da cultura das comunidades tradicionais, dentre outros.
Na escola, observou-se que o público alvo seria mais homogêneo, pois todos eram professores, no qual se esperava que grande parte tivesse curso superior. Os participantes poderiam ser do ensino infantil e fundamental, de todas as disciplinas do ciclo básico. Esse público alvo também era variável em relação à idade, e tempo de experiência.

Para a etapa 5, teve-se em atenção o vasto conhecimento que esses atores locais possuem da área de estudo, por isso, o curso foi delineado de forma a valorizar esses saberes e experiências, dando destaque para características físicas e histórico-culturais, experiências de campo, conhecimento sobre novos pontos de interesse geológico que não constavam no inventário, reflexões sobre a gestão do território e os conflitos socioambientais.

Com base nesses elementos, a proposta discutida para os cursos teve como sustentação três principais elementos: promover a Geoconservação através dos cursos, valorizar os saberes locais e a experiência desses profissionais e dar autonomia para os atores locais a fim de que as estratégias tenham continuidade.

Para tanto, o referencial teórico e metodológico utilizado pautou-se em experiências similares que trazem a abordagem da Aprendizagem Social e da Participação (Bacci et al. 2013, Jacobi 2011 e 2013, Santos 2006 e 2011, Soares 2016). A Aprendizagem Social pressupõe ações que reúnam uma diversidade de atores sociais mobilizados na resolução de uma problemática. No contexto educativo, a Aprendizagem Social valoriza a interdisciplinaridade entre diversos saberes e a participação de diferentes atores sociais em decorrência das transformações socioambientais (Monteiro 2009). Como aponta Jacobi (2011, p. 13), pensar a participação requer num primeiro momento o "acesso à informação e sua difusão com o objetivo de ampliar o envolvimento do cidadão".

Monteiro (2009) destaca três aspectos da Aprendizagem Social que corroboram com as reflexões desenvolvidas durante os cursos. Para o autor, num primeiro momento a Aprendizagem Social se refere à forma como os indivíduos constroem suas "visões de mundo", ou seja, quais as formas e processos pelos quais os indivíduos dão sentido à realidade. O segundo aspecto refere-se aos "conceitos", ou seja, a Aprendizagem Social prioriza um olhar holístico e sistêmico, reforçando as interdependências entre os elementos. Como terceiro aspecto, observa as "relações e interações entre os indivíduos", reforçando a importância dos diálo-

\begin{tabular}{c|c|c|c|c|c|}
\hline (C) Terrae Didat. & Campinas, SP & v.14 & n.4 & p. 417-426 & out./dez. 2018 \\
\hline
\end{tabular}


gos e das conversas significativas ao proporcionar reflexões sobre suas concepções, valores e práticas, tendo como referência a participação social.

Portanto, o curso foi elaborado tendo como pressuposto a aprendizagem em comunidade, valorizando os saberes locais e os diálogos voltados para a Geoconservação.

Nesse sentido, o arcabouço teórico também esteve pautado na literatura referente ao ensino de Geociências, considerando a Terra como um Sistema, e reforçando a visão integradora e interdisciplinar. Além disso, considerou-se importante a valorização dos aspectos locais e regionais através da problematização dos elementos e do desenvolvimento de trabalhos de campo para essa aprendizagem e apropriação dos conceitos.

$\mathrm{Na}$ definição dos conteúdos, referente à sexta etapa, considerou-se as seguintes temáticas: conservação da natureza, introdução às Geociências, Geodiversidade, Patrimônio Geológico e Geoconservação. As estratégias utilizadas durante o curso foram basicamente aulas dialogadas, o uso de metodologias participativas e o trabalho de campo, que serão melhores discutidas no próximo ítem.

\subsection{Conteúdos, atividades e 0 uso de Metodologias Participativas}

A duração do curso foi de dois dias em cada um dos núcleos do PESM (total de 16h cada), e de quatro dias na escola (total de $30 \mathrm{~h}$ ). Os temas e conteúdos abordados com os monitores ambientais e professores tiveram algumas particularidades, mas de modo geral seguiram os seguintes eixos temáticos:

- Geodiversidade e Patrimônio Geológico: abordagem das relações entre a UC, a escola e a questão socioambiental, destacando a contribuição das Geociências para o estudo do ambiente;

- Educação e Aprendizagem Social: promoção de reflexões sobre a importância do desenvolvimento de práticas educativas colaborativas pautadas em princípios de diálogo, participação e co-responsabilização frente às questões socioambientais locais com referência no conceito de aprendizagem social, bem como apresentar diferentes metodologias participativas;

- Roteiros Geológicos: realização de visitas técnicas em trilhas do parque ou de seu entorno que contemplem aspectos geológicos, geomor- fológicos, históricos, arqueológicos e culturais de significativa expressão local/regional observando e refletindo sobre os geossítios, visando $\mathrm{o}(\mathrm{re})$ conhecimento desses aspectos e a análise crítica do lugar.

- Propostas de Geoconservação para a UC: reflexões sobre as ameaças a que os geossítios estão sujeitos e sua necessidade de conservação, visando à elaboração de propostas colaborativas;

Para as aulas dialogadas, foram utilizados datashow, lousa, amostras de rochas coletadas na região e os painéis de interpretação geológica do litoral norte paulista elaborado pelo NAP GeoHereditas ${ }^{1}$.

Com relação às atividades participativas, foram elaboradas três propostas (Tab. 1) com base no referencial da Aprendizagem Social e das Metodologias Participativas.

O world café, baseado nos estudos de Brown (2001), Camargo (2011) e Fernandes (2015), consiste numa metodologia participativa que busca reunir grupos de atores sociais diversos para estabelecer diálogos significativos em torno de questões centrais, procurando delimitar possíveis caminhos e soluções para essas questões. No curso proposto, foram elaboradas quatro questões relacionadas à Geoconservação e aos conflitos socioambientais locais, sendo elas: a) Há necessidade da Geoconservação na região? Por quê? Se sim, o que precisa ser feito? b) O Plano de Manejo abrange a geodiversidade? $\mathrm{O}$ que você incluiria ou acrescentaria ao Plano de Manejo? c) Quais caminhos devem ser seguidos para a Geoconservação nos programas de Educação Ambiental e Educação Patrimonial? d) Quais locais podem ser considerados importantes para a Geoconservação? Por quê? Como valorizá-los?

Os participantes foram divididos em grupos e cada grupo respondeu às quatro questões, sendo que as ideias de cada grupo foram posteriormente compartilhadas com todos.

O Mapeamento Socioambiental foi desenvolvido com base em Santos $(2006,2011)$, Santos \& Bacci (2011), Bacci \& Santos (2013), e Oliveira (2016). Essa metodologia se refere a um tipo de mapeamento realizado em campo que busca, a partir da observação, do diálogo e da reflexão, perceber o lugar de um modo diferente, identificar elementos novos, 1 Disponíveis em: < http://www.igc.usp.br/index. php?id $=987>$ 
Tabela 1. Atividades participativas preparadas para os cursos

\begin{tabular}{l|l|l}
\hline Atividade & Público-alvo & Material \\
\hline $\begin{array}{l}\text { Valores/ } \\
\text { Ameaças/ } \\
\text { estratégias }\end{array}$ & Monitores ambientais & Cartolina e canetas coloridas \\
\hline World café & Monitores ambientais & Cartolina e canetas coloridas \\
\hline $\begin{array}{l}\text { Mapeamento } \\
\text { Socioambiental }\end{array}$ & Professores & Mapa base, prancheta, canetas coloridas e roteiro geointerpretativo \\
\hline
\end{tabular}

* Após apresentação dos conceitos da geodiversidade local, a primeira atividade consistiu em levantar os valores, as ameaças e possíveis estratégias de Geoconservação com base em geossítios escolhidos pelos grupos de participantes, os quais poderiam ser locais já inventariados ou, outros locais que eles considerassem relevantes do ponto de vista geológico.

interpretar e relacionar o ambiente biofísico, as relações humanas, os aspectos históricos, os conflitos e problemas enfrentados. Espera-se que essa mudança de percepção entre os participantes faça emergir reflexões e questionamentos sobre como solucionar os conflitos identificados e sobre a responsabilidade de cada um dos atores sociais envolvidos.

Para o desenvolvimento do Mapeamento Socioambiental com ênfase na Geoconservação, definiu-se como roteiro uma área próxima à escola, o qual percorria área de planície, restinga e da praia. Mazzucato (2017) elaborou o roteiro geointerpretativo como material de apoio para o percurso. Os participantes foram divididos em grupos, e cada um recebeu um mapa base do local que deveria ser preenchido com novas informações à medida que o percurso era feito, dando destaque ao princípio V.E.R.A.H (Vegetação, Erosão, Resíduos Sólidos, Água, Habitação), incluindo nessa dinâmica os elementos da geodiversidade apreendidos em aula. Após o trabalho de campo os participantes discutiram os elementos observados e refletiram sobre as observações feitas. Desse modo foi composto o mapa síntese colaborativo contendo os elementos observados, incluindo apontamentos críticos e propositivos para a região.

Com relação aos trabalhos de campo foram definidos roteiros diferentes para cada um dos cursos. Em Picinguaba o roteiro utilizado foi a "Trilha do Saco das Taquaras", que é parte da "Trilha Brava da Almada”. Em Caraguatatuba percorreu-se a "Trilha do Jequitibá" e, com a escola de Ubatuba, criou-se um roteiro na praia do Puruba.

Os objetivos dos trabalhos de campo foram de promover uma observação direcionada e ampliar os conteúdos teóricos sobre geodiversidade e patrimônio local, correlacionando-os à realidade socioambiental. Os trabalhos de campo foram desenvolvidos de acordo com as seguintes temáticas: interação entre geodiversidade e biodiversidade, tipos de solo, dinâmica fluvial e costeira, a formação da areia da praia, capacidade de transporte dos rios, abertura e fragmentação do Supercontinente Gondwana, formação das ilhas na região, bem como das intrusões de diques de rochas magmáticas e do relevo da Serra do Mar como consequência desses eventos geológicos e interações sociais e conflitos sociais em UCs.

\subsection{Reflexões e avaliação}

Em relação à aprendizagem e aos resultados dos cursos, a análise se deu com base nos materiais elaborados durante o desenvolvimento das metodologias participativas, bem como na observação e posterior análise do desencadeamento das discussões e a postura investigativa e questionadora dos participantes, ou seja, em métodos de avaliação formativa.

Observou-se que a efetividade do curso teve profunda relação com as parcerias estabelecidas, e com o interesse voluntário dessas instituições e dos participantes dos cursos em apreender uma nova forma de olhar para a realidade local, ampliando seus saberes em relação às Geociências e também exercitando seu papel de importante ator social da região. Os monitores ambientais, gestores da UC e professores constituem-se em fortes grupos de atuação local, promotores de mudanças e formadores de opinião na comunidade. Além disso, ambos os grupos poderiam claramente incorporar esses novos conhecimentos em suas práticas. No caso dos monitores, com a possibilidade de agregar informações no monitoramento das trilhas junto aos turistas, pesquisadores, alunos e outros. Além disso, esse grupo atua diretamente nas trilhas, orientando e monitorando pontos de interesse geológico e sua proteção. Com relação aos professores, observa-se que a escola é um ponto central para a divulgação das Geociências e para a sensibilização para a Geoconservação, com compromisso social de abordar temas de relevância local, formando e capacitando os estudantes para discutir os problemas e conflitos na região.

Por valorizar a participação e a autonomia dos 
participantes em definir as estratégias de Geoconservação e refletir sobre os problemas locais, ambos os grupos demonstraram interesse em dar prosseguimento aos assuntos discutidos, refletindo sobre a gestão municipal e também da UC. Nesse sentido, grande parte revelou participar de reuniões, além de liderar e ou participar de associações de bairro e realizar projetos com as comunidades locais, o que poderá influenciar a inserção da Geoconservação nessas pautas e ampliar a divulgação e valorização do patrimônio geológico local.

Alguns problemas foram observados em relação à utilização de inventários científicos para a elaboração dos cursos, a exemplo alguns geossítios que possuem valor educativo, mas que tem como público alvo alunos do ensino superior. Portanto, mesmo disponibilizando os inventários da região, este deve ser trabalhado do ponto de vista educativo, e, principalmente, os locais reconhecidos pelos participantes devem ser valorizados e interpretados, representando um alto potencial de levantamento de geossítios como forma de complementar o inventário.

Por tratar-se de uma área de floresta altamente preservada, observou-se que os participantes estabeleciam fortes relações da geodiversidade com a biodiversidade, além de considerar os aspectos culturais locais. Portanto, abordagens que apresentem esses contextos e relações podem resultar em aprendizagens mais efetivas.

Inúmeras questões emergiram ao longo do curso, mas principalmente no trabalho de campo, revelando que o campo permitiu uma maior aproximação dos participantes para com os ministrantes do curso, enriquecendo de modo singular a formação proposta. Também foi possível observar que para grande parte dos professores, o trabalho de campo permitiu o conhecimento do entorno da escola e das particularidades geocientíficas do lugar, além de se configurar em estratégia educativa que poderá ser adotada na escola.

Deve-se atentar fortemente para a linguagem e o nível de profundidade com que os temas são abordados, pois isso pode causar distanciamento e frustração nos participantes. Essa observação revela a precária formação em Geociências que a sociedade como um todo possui. Mesmo tendo conhecimento desse fato, em vários momentos foi necessário adequar o conteúdo e a linguagem de modo a facilitar o entendimento. Observa-se que a área da Geoconservação pode ser uma estratégia interessante para divulgar as Geociências para o público em geral e para o escolar, subsidiando conhecimentos que não estão nos currículos.

Apesar de a principal abordagem favorecer a educação e a divulgação, os participantes salientaram em diversos momentos sua preocupação com a visitação dos geossítios, devido à falta de sinalização ou infraestruturas de acesso. No caso dos monitores ambientais, observou-se um olhar mais atento aos valores turísticos da geodiversidade. A abordagem educativa priorizada pelos monitores nesse contexto foi de sensibilizar e despertar os visitantes para esses aspectos, visto que a trilha não se trata de um processo educativo, mas sim, uma experiência turística diferenciada, de valorização da natureza e apoio à sua conservação.

Contudo, no caso dos professores, houve percepção das potencialidades educativas inerentes aos geossítios e à temática da Geoconservação, nesse caso os professores revelaram a necessidade de um trabalho em conjunto e interdisciplinar. Diversas discussões suscitaram a preocupação que esses participantes possuem sobre a gestão da geodiversidade e a exploração dos recursos naturais.

Entretanto, houve um reconhecimento, tanto por parte dos participantes quanto dos pesquisadores de que para uma maior aprendizagem e maiores direcionamentos para a Geoconservação local há necessidade de cursos de formação de longo prazo, requerendo para isso maiores recursos e ampliação de parcerias com a diretoria de ensino, secretarias municipais de educação, ONGs, equipes formadoras e público de forma geral.

\section{Conclusão}

O curso desenvolvido na área de estudo se mostrou uma experiência singular, pois, se baseou em práticas consolidadas em metodologias de ensino de Geociências e da Aprendizagem Social para divulgar e promover a Geoconservação. Com esse relato, espera-se orientar outros procedimentos nessa área, reforçando que a área da Geoconservação possibilita inúmeras abordagens que podem ser a porta de entrada para a divulgação científica. Da mesma forma que o ensino de Geociências é um dos pilares para o estabelecimento de estratégias de Geoconservação. Salienta-se ainda que a pesquisa nessa área não foi algo linear e fechado. Mesmo havendo um projeto norteador, a trajetória, os objetivos e metodologias foram se adequando à medida que a pesquisa evoluiu com a colaboração de diversas pessoas.

Ter contato com esses atores locais em parti-

\begin{tabular}{c|c|c|c|c|c|}
\hline (C) Terrae Didat. & Campinas, SP & v.14 & n.4 & p. 417-426 & out./dez. 2018 \\
\hline
\end{tabular}


cular e poder ouvir e apreender seu modo de olhar para a realidade enriqueceu o curso e facilitou o processo de aprendizagem, bem como de prosseguimentos à Geoconservação.

Salienta-se ainda que a pré-existência de um inventário científico foi essencial para o desenvolvimento da pesquisa, orientando a formulação dos cursos e refletindo sobre o contexto da área de estudo.

\section{Agradecimentos}

Agradecemos ao Instituto de Geociências e ao CNPq pela concessão de bolsa de mestrado (Processo $n^{\circ}$ 134633/2015-6). Ao NAP GeoHereditas e aos funcionários do Parque Estadual da Serra do Mar, núcleos Picinguaba e Caraguatatuba, bem como aos gestores da escola municipal de Ubatuba, por viabilizarem a realização dos cursos. Aos monitores ambientais, funcionários da UC e professores que voluntariamente participaram do curso.

\section{Referências}

Aguilar A.P., Barros E.J., Andrade M.R.M., Oliveira E.S., Juliani C., Oliveira A.M.S. 2012. Geoparque Ciclo do Ouro, Guarulhos (SP): propostas. In: Schobbenhaus C., Silva C.R. orgs. 2012. Geoparques do Brasil: propostas. Rio de Janeiro: CPRM. p. 543-582.

Almeida F.F.M.de, Hasui Y., Brito Neves B.B., Fuck R.A. 1977. Províncias estruturais brasileiras. In: Simp. Geol. Nordeste, 7, Campina Grande. Atas... Campina Grande, SBG. (B. Esp.). p. 363-391.

Almeida F.F.M.de, Hasui Y., Brito Neves B.B., Fuck R.A. 1981. Brazilian Structural Provinces: an introduction. Earth-Science Reviews, 17(1-2):1-29.

Arruda K.E.C. 2017. A Geoconservação como subsídio à gestão territorial sustentável: o mapa geoturístico do litoral norte do Estado de São Paulo. 190p. São Paulo: Inst. Geoc., USP. (Tese, Dout. Ciências).

Avelar S., Mansur K.L., Anjos S.C., Vasconcelos G.F. 2016. Community Perceptions for Geoconservation of a Coastal Area in Rio de Janeiro, Brazil. Geoheritage, 7(3): 275 - 283.

Bacci D.C., Jacobi P.R., Santos V.M.N. 2013. Aprendizagem Social nas Práticas Colaborativas: exemplos de ferramentas participativas envolvendo diferentes atores sociais. Alexandria, 6(3): 227-243.

Bacci D.B., Santos V.M.N. 2013. Mapeamento socioambiental como contribuição metodológica à formação de professores e aprendizagem social. Geologia USP, Publ. Espec., São Paulo, 6: 19-28.

Brilha J.B. 2005. Património Geológico e Geoconservação: a Conservação da Natureza na sua Vertente Geológica. Viseu: Palimage. 190p.

Brown J. 2001. The World Café: Living knowledge through conversations that matter. The Fielding Institute. PhD Dissertation. URL: http://www. theworldcafe.com. Acesso: 05.02. 2018.

Camargo M.E. 2011. World Café: Métodos de diálogo e criação coletiva como ferramenta de Educação Ambiental. In: Jacobi P.R. coord. 2011. Aprendizagem Social: Diálogos e Ferramentas Participativas: Aprender juntos para cuidar da água. São Paulo: IEE/PROCAM. p. 33-36.

Carvalho I.C.M. 2008. Educação Ambiental: a formação do sujeito ecológico. 3 ed. São Paulo: Cortez. 255p.

Fernandes M.E.S.A.C. 2015. O World Café e o aprendizado pelo diálogo: limites e possibilidades de um território de sentidos no processo de formação "Diagnóstico socioambiental na APA Embu Verde: Educação Ambiental para a sustentabilidade na bacia do rio Cotia”, Embu das Artes, SP. 210p. São Paulo: Fac. de Educ., USP. (Tese, Dout. Educ.).

Garcia M.G.M., Brilha J., Lima F.F., et al. 2013. The inventory of Geological Heritage of the State of São Paulo, Brazil: Methodological Basis, Results and Perspectives. Geoheritage, 10(2): 239-258.

Jacobi P.R. coord. 2011. Aprendizagem Social: diálogos e ferramentas participativas: aprender juntos para cuidar da água. São Paulo: IEE/PROCAM. 86p.

Jacobi P.R. coord. 2013. Aprendizagem social e unidades de conservação: aprender juntos para cuidar dos recursos naturais. São Paulo: IEE/PROCAM. 94p.

Mansur K.L., Rocha A.J.D., Pedreira A. et al. 2013. Iniciativas institucionais de valorização do patrimônio geológico do Brasil. Bol. Paranaense de Geociências. 70: $02-27$.

Mansur K., Guedes E., Alves M.G., Nascimento V., Pressi L.F., Costa Jr. N., Pessanha A., Nascimento L.H., Vasconcelos G. 2012. Geoparque Costões e Lagunas no Estado do Rio de Janeiro (RJ): proposta. In: Schobbenhaus C., Silva C.R. orgs. Geoparques do Brasil: propostas. Rio de Janeiro: CPRM. p. 687-745.

Mazzucato E. 2017. Estratégias de Geoconservação no Parque Estadual da Serra do Mar - núcleos Picinguaba e Caraguatatuba (SP). 320p. São Paulo: Inst. Geoc., USP. (Dissert. Mestrado).

Monteiro F.M. 2009. Aprendizagem Social e Educação para Sustentabilidade. In: Jacobi P.R., Monteiro F., Fernandes M.L.B. Educação e Sustentabilidade: caminhos e práticas para uma educação transformadora. São Paulo: Evoluir Cultural. 108p.

Oliveira, A.M.S. 2016. Educação Ambiental transformadora. O método VERAH. São Paulo: Ícone. 112p.

Perrotta M.M., Salvador E.D., Lopes R.C., D'Agostino L.Z., Peruffo N., Gomes S.D., Sachs L.L.B., Meira V.T., Garcia M.G.M., Lacerda Filho J.V. 2005. Mapa Geológico do Estado de São Paulo, escala: 1:750 000. São Paulo: Programa Geologia do Brasil, PGB, CPRM.

Schobbenhaus C., Campos D.A., Queiroz E.T., Winge M., Berbert-Born M.L.C. eds. 2002. Sítios Geológicos e Paleontológicos do Brasil. Brasília: DNPM. 554p.

Schobbenhaus C., Silva C.R. orgs. 2012. Geoparques do Brasil: propostas. Rio de Janeiro: CPRM. 748p.

Soares D.B. 2016. Formação continuada de professores em geociências com metodologias participativas: contribuições à educação para geoconservação. 189p. Campinas: Inst. Geoc., UNICAMP. (Dissert. Mestrado).

Winge M., Schobbenhaus C., Souza C.R.G., Fernandes A.C.S., Berbert-Born M., Queiroz E.T., Campos

\begin{tabular}{c|c|c|c|c|c}
\hline (C) Terrae Didat. & Campinas, SP & v.14 & n.4 & p. 417-426 & out./dez. 2018 \\
\hline
\end{tabular}


D.A. eds. 2009. Sítios geológicos e paleontológicos do Brasil. Brasília: CPRM, v. 2. 515p.

Santos P.L.A. 2014. Patrimônio Geológico em áreas de proteção ambiental: Ubatuba-SP. 207 p. São Paulo: Inst. Geoc., USP. (Dissert. Mestrado).

Santos V.M.N. 2006. Formação de professores para o estudo do ambiente: projetos escolares e a realidade socioambiental local. 279p. Campinas: Inst. Geoc., UNICAMP. (Tese, Dout. em Ciências).

Santos V.M.N. 2011. Educar no ambiente: Construção do olhar geocientífico e cidadania. São Paulo: Annablume. 178p.

Santos V.M.N., Bacci D.C. 2011. Mapeamento socioambiental para Aprendizagem Social. In: Jacobi P.R. coord. Aprendizagem social: diálogos e ferramentas participativas: aprender juntos para cuidar da água. São Paulo: IEE/PROCAM. p. 63-85.
São Paulo. Secretaria do Meio Ambiente. 2006. Plano de Manejo do Parque Estadual da Serra do Mar. São Paulo: Instituto Federal. 441p.

São Paulo. 2010. Decreto $n^{\circ}$ 56.572, de 22 de dezembro de 2010. Dispõe sobre a expansão do Parque Estadual da Serra do Mar em áreas de domínio público e dá providências correlatas. DOU, São Paulo, SP, 23 dez. 2010

São Paulo. 2014. Secretaria do Meio Ambiente. Fundação para a Conservação e a Produção Florestal. Manual de Gestão das Unidades de Conservação do Estado de São Paulo. São Paulo: Páginas \& Letras. 328p.

Winge M., Schobbenhaus C., Souza C.R.G., Fernandes A.C.S., Berbert-Born M., Filho W.S., Queiroz E.T. eds. 2013. Sítios Geológicos e paleontológicos do Brasil. Brasília: CPRM. v. 3. 332p. 